\title{
Research on Thermal Insulation Characteristic of Multilayer Clothing
}

\author{
T.Anusha, V.A.Rinsey Antony, P.Jayashri
}

\begin{abstract}
Winter outdoor clothing is aimed at protecting human being against harsh environmental conditions, especially against cold. Thermal insulating properties of a textile material plays significant role in protective clothing. Thermal protective clothing usually is a multilayer construction composed of three layers -Base layer, Insulating material, Outer layer. The previously available jacket insulating layer is always filled with down feather which cause harm to the wearer. This study concentrates on replacing the middle layer with ecofriendly natural Fiber-Kapok. Thickness, thermal conductivity, Air permeability, and wickability properties of fiber and fabric is determined. The layers are been bonded with Needle punching and thermal bonding technique. The effect of Multilayer clothing in cold weather is been tested and analyzed using different proportions of natural ecofriendly-kapok fiber.
\end{abstract}

Keywords: Multilayer clothing, Kapok, Needle punching, Thermal Bonding

\section{INTRODUCTION}

Winter outside article of clothing is geared toward protective creature against harsh environmental conditions, particularly against cold. Thermal insulating properties of a textile material plays important role in protecting article of clothing. Thermal protecting article of clothing sometimes could be a multilayer construction and antecedently developed jackets consists of 3 layers:

o Base layer

o Insulating material

o Outer layer

\subsection{Base Layer:}

The base layer is sometimes fabricated from man-made fiber like polyester that is hydrophobic in nature and fast drying. It are often insulation by producing bless fiber. Polyester retains its form and thus it's sensible for creating outside article of clothing for harsh climates. A base layer is that the layer nighest to your skin, that means it collects the foremost sweat. the aim of this layer is to stay you dry by actuation wetness faraway from your skin and spreading it throughout the material. At constant time this cloth ought to work snugly and retain some insulating properties. ne'er wear cotton as a base layer, that will wick wetness away, on the other hand retains that wetness because the cotton loses its resiliency, loses its heat, and causes an excessive amount of physical change cooling.

Revised Manuscript Received on September 14, 2019.

T.Anusha, Assistant professor, Department of Costume Design and Fashion, Sri Krishna Arts and Science College, Coimbatore, Tamilnadu, India.

V.A.Rinsey Antony, Head of the Department, Department of Costume Design and Fashion, Sri Krishna Arts and Science College, Coimbatore, Tamilnadu, India. Fashion, Sri Krishna Arts and Science College, , Coimbatore, Tamilnadu, India.
P.Jayashri, Assistant professor, Department of Costume Design and

\subsection{Outer Layer:}

The Outer layer protective against wind and precipitation .this layer additionally creates a shell on that different practical components of clothing area unit placed. Outer layer is created from polymer membrane. it's flexibility, abrasion and tear resistance is nice and has high sturdiness and color ranges. A technical outer shell is constructed of materials that supply each breathability and waterresistance, a technical outer shell understands that your outside way can cycle between sweating sort of a pig and hunkering down from the storm. the first operate of a shell is to guard you from the weather once conditions take a flip for the worst. Two flavors of outer shells area unit offered: arduous and soft. A soft shell are a lot of versatile and breathable, could also be water resistant, however not waterproof. Some go with a laminated windproof membrane, others do not. a tough shell are each waterproof and windproof however not as breathable. looking on the categories of conditions you propose on heading call at, one or the opposite could also be a lot of acceptable. If sustained rain conditions may occur, there's no replacement for a water-proof arduous shell. the most effective can provide taped seams, waterproof zipper systems, multiple layers, and materials that supply some breathability even supposing they're waterproof.

\subsection{Middle Layer:}

Middle layer is thermal insulating layer, it's got multilayer structure so as to confirm thermal comfort in winter outside atmospheric condition. the center thermo insulating layer fabricated from thermal insulating materials like down feathers, it protects the organic structure from excessive heat loss. it's direct influence of the warmth energy and coupling impact. associate degree insulation layer, whether or not artificial or down, provides additional loft and heat, basically doing what a thick mid-layer will, however increased, and with a way higher warmth-to-weight quantitative relation

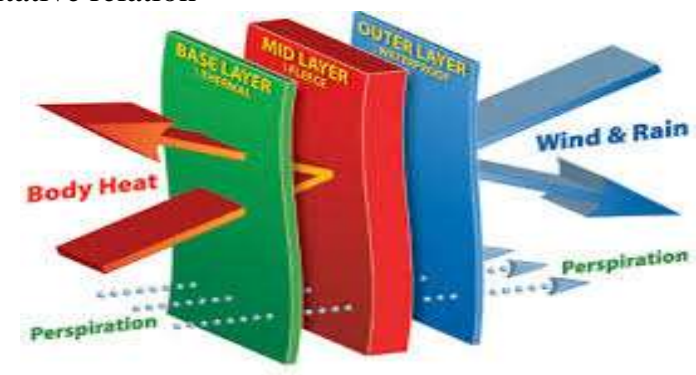

Fig.1.1 Multilayer

Published By: 
The middle layer which consist of down is a good thermal insulator and are widely used. However it is often obtained by subjecting ducks, geese and swans. It is found that feather removal is likely to be painful and can categorized as an ethical problem.

Another drawback is they also lead to allergic problems. Considering these drawbacks a potential alternative to down insulation is made.

The primary condition for clothing comfort of cold weather is to state by thermal insulation and permeability (air and water) to maintain the warmth condition. The water vapor and moisture transport from the skin through clothing to the environment in cold weather and its dependence on clothing thermal and evaporative resistances and layering in cold clothing designs. Moreover thermal insulation and number other requirements are protection against wind, rain and snow. The most important properties of cold weather clothing are insulation and breathability. In cold weather the clothing should provide the required insulation for protection against the cold and it should allow the transmission of perspired sweat from the skin to the environment. The insulation and permeability determines the amount of heat and moisture exchanged between body and environment is to maintain the wearer dry and warm.

Cold weather clothing required high level of protection from extreme cold and wind conditions. The design and development of cold weather clothing is challenging and critical process. The selection of suitable textile material for cold weather clothing minimizing the physical stress on the wearer.

Wool and pile fabric have been used for the cold weather clothing in ancient times. After that the synthetic fibers like polyester and acrylic were used in making the cold weather clothing. The researches have been carried out to develop new and effective synthetic insulating materials to provide protection against cold.

\section{Put goose down filling:}

This research focuses on development of natural fiber based multi-layer clothing is to overcome the already available goose down multi-layer clothing for extreme cold weather. In this research micro denier polyester base layer, kapok fiber filled middle layer and fleece outer shell layer were developed for this study. The developed sample were tested the thickness, thermal insulation, water vapor permeability and air permeability were analyzed.

\section{MATERIALS AND METHODOLOGY}

TRIALED METHODOLOGY:

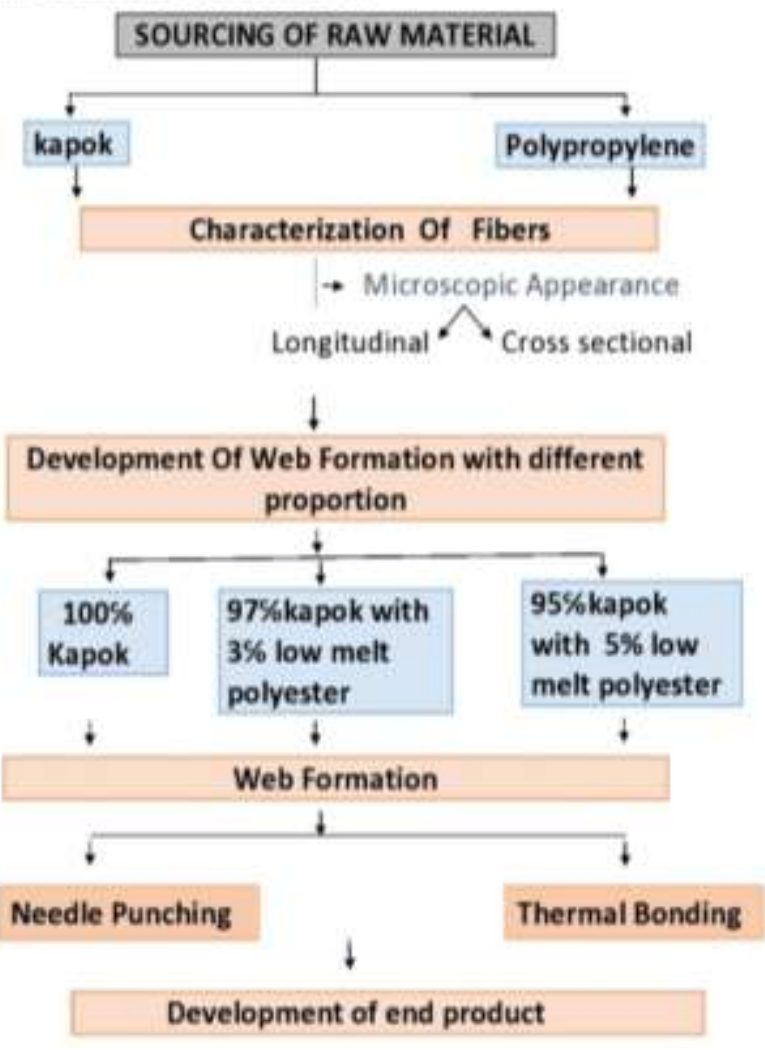

ACHIEVED METHODOLOGY:

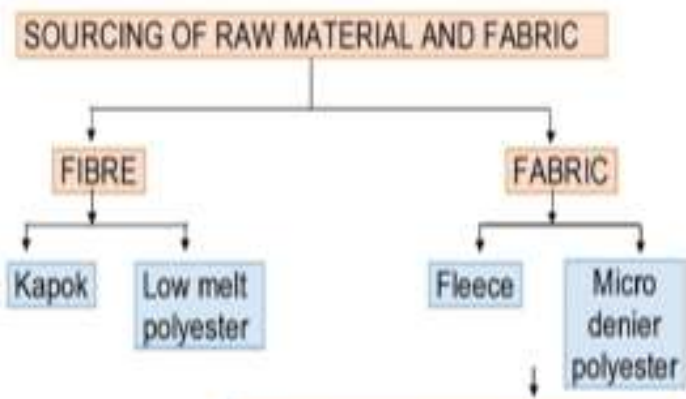

Physical properties of fabric
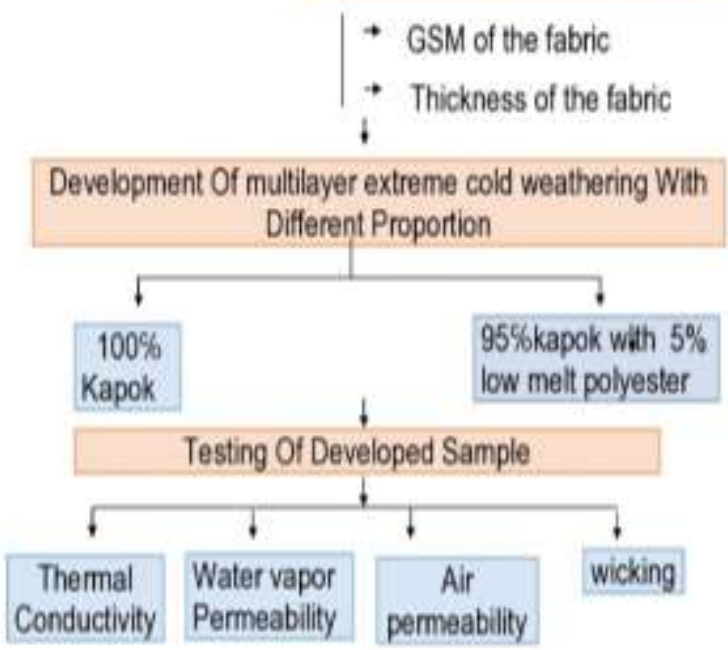


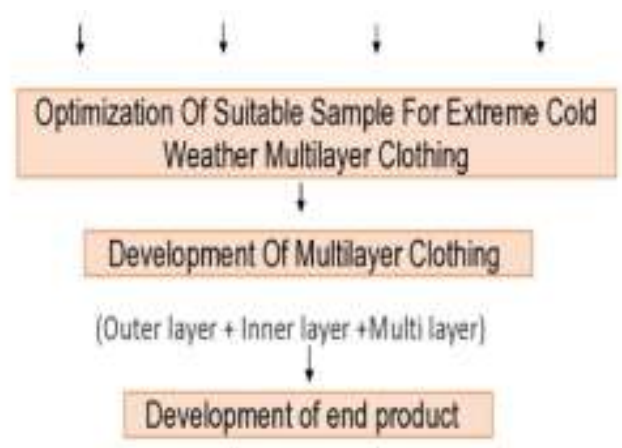

\subsection{Materials:}

First trial, Kapok and polypropylene were purchased from kowishkka silk cotton and mattress, Dindigul, second trial, kapok was purchased from local distributor, Tirpur, Fleece fabric ( 248 GSM and Thickness of 1.058) was purchased from Tirpur, and micro denier polyester fabric (170 GSM and Thickness of 0.342) and low melt polyester were purchased from apparel industry Tirpur.

\subsection{Methods:}

\subsubsection{Trialed Methods:}

- Web formation

$\circ \quad$ Needle punching technique.

- Thermal bonding technique.

\section{Needle punching technique:}

Web formation is made with kapok and polypropylene (which is sourced from dindigul) by utilizing the machines available in textile department PSG, with different proportions of kapok and its blends as follows:

\section{○ $\quad 100 \%$ kapok \\ - $\quad 97 \%$ kapok with $3 \%$ polypropylene \\ ○ $\quad 95 \%$ kapok with $5 \%$ polypropylene}

After web formation, needle punching technique is tried in PSG INDO-TECH Centre of Excellence (COE) Neelambur, Coimbatore. Due to some technical issues we couldn't complete needle punching technique with that formed web.

Secondly, the both web formation and needle punching was done with the same proportion as mentioned above, in PSG INDO-TECH Centre of Excellence (COE) Neelambur, Coimbatore. Where the web formation was uneven due to the loftiness of the kapok. Though the web formation was uneven we tried for needle punching with those loosely packed web.

Even in the second attempt of needle punching the result wasn't good due to the less strength of the fiber. Even then the other attempt was made with other technique (thermal bonding).

\section{Thermal bonding technique:}

As we discussed previously the thermal bonding technique was tried from the formed web during the needle punching technique again due to some problem in the properties of fiber, still then the result wasn't good.

Even after many attempts were made to source finer quality fiber at last we got the best quality kapok fiber from a local distributor, tirpur. Though we got finer property fiber still the web formation was not possible with polypropylene blend with the proportion as mentioned above. Since, the main aim of the project is to produce eco-friendly and cruelty free natural fiber in the place of down feather so, again thermal bonding technique was adopted, by keeping kapok constantly by making alteration in its blend i.e., polypropylene was replaced with low melt polyester with different proportion as follows:

- $\quad 70 \%$ kapok with $30 \%$ low melt polyester.

- $\quad 80 \%$ kapok with $20 \%$ low melt polyester.

Then the thermal bonding was carried out with $110^{\circ} \mathrm{C}$ upto $130^{\circ} \mathrm{c}$ and then with $150^{\circ} \mathrm{c}$ up to the maximum of $180^{\circ} \mathrm{c}$, where it still resulted in a failure. There is lack of time duration for completion of project work we adopted the other technique.

\subsubsection{Achieved Method:}

In the recently available multilayer cold weather clothing with goose down, filling technique was followed. Since time wasn't sufficient to source different quality fiber that would be applicable for the needle punching and thermal bonding techniques, the previously adopted method was used. Where instead of using needle punching or the thermal bonding technique, filling technique was carried out with two different proportion:

○ $100 \%$ kapok.

○ $\quad 95 \%$ Kapok with 5\% polypropylene.

\section{RESULTS AND DISCUSSION}

Kapok with low melt polyester blends sample was prepared by filling technique. Evaluation of samples were carried out to determine the GSM, thickness, thermal conductivity, water vapor permeability, air permeability and wicking. The results of the tested samples were discussed below.

\subsection{GSM:}

\subsubsection{GSM Of Fleece:}

Table 3.1 GSM of Fleece fabric

\begin{tabular}{|l|l|l|}
\hline $\begin{array}{l}\text { SERIAL } \\
\text { NO. }\end{array}$ & SAMPLES & GSM VALUE \\
\hline 1 & Sample -1 & 2.441 \\
\hline 2 & Sample -2 & 2.552 \\
\hline 3 & Sample -3 & 2.385 \\
\hline 4 & Sample -4 & 2.625 \\
\hline 5 & Sample -5 & 2.412 \\
\hline
\end{tabular}

Calculation:

Average $=12.415 / 5$

$$
=2.483 \times 100=248
$$

\section{GSM of the Fleece fabric $=248$ GSM}

In the above table 3. 1. The GSM of the fabric and the number of samples. Likewise readings were obtained from five different samples of the same fabric and the average value gives the GSM of the fleece fabric. 


\subsubsection{GSM Of Micro Denier Polyester:}

Table 3.2 GSM of Micro Denier Polyester

\begin{tabular}{|l|l|l|}
\hline $\begin{array}{l}\text { SERIAL } \\
\text { NO. }\end{array}$ & SAMPLES & GSM VALUE \\
\hline 1 & Sample -1 & 1.731 \\
\hline 2 & Sample -2 & 1.854 \\
\hline 3 & Sample -3 & 1.685 \\
\hline 4 & Sample -4 & 1.761 \\
\hline 5 & Sample -5 & 1.652 \\
\hline
\end{tabular}

\section{Calculation:}

Average $=8.683 / 5$

$$
=1.7366 \times 100=173
$$

GSM of the Micro Denier polyester fabric $=173 \mathrm{GSM}$

In the above Table 3.2 shows the GSM of the fabric and the number of samples. Likewise readings are obtained from five different samples of the same fabric and the average value gives the GSM of the micro denier polyester fabric.

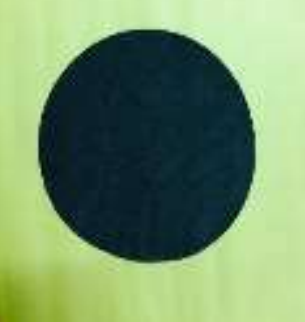

MDP

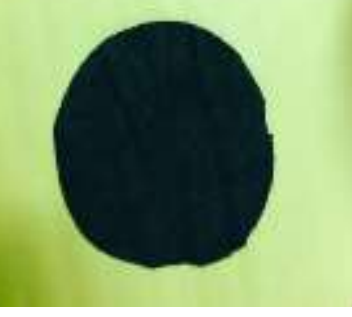

FLEECE

\subsection{Thickness}

\subsubsection{Thickness Of Fleece:}

Table 3.3 Thickness of Fleece fabric

\begin{tabular}{|l|l|}
\hline SERIAL.NO & $\begin{array}{l}\text { THICKNESS VALUE OF } \\
\text { FLEECE }\end{array}$ \\
\hline 1 & 1.21 \\
\hline 2 & 1.21 \\
\hline 3 & 1.26 \\
\hline 5 & 1.27 \\
\hline
\end{tabular}

\section{Calculation:}

Thickness $=5.294 / 5$

$$
=1.058
$$

Thickness of Fleece fabric $=\mathbf{1 . 0 5 8}$

The above Table.3.3 represents the thickness of the fabric and the number of samples. Likewise readings are obtained from five different area of the sample in the same fabric and the average value gives the thickness of the fleece fabric.

3.2.2 Thickness Of Micro Denier Polyester:

Table 3.4 thickness of Micro Denier Polyester

\begin{tabular}{|l|l|}
\hline SERIAL.NO & THICKNESS VALUE OF FLEECE \\
\hline 1 & 0.35 \\
\hline 2 & 0.34 \\
\hline 3 & 0.35 \\
\hline 4 & 0.34 \\
\hline 5 & 0.33 \\
\hline
\end{tabular}

Calculation:

Thickness $=1.71 / 5$

\section{$=0.342$}

\section{Thickness of Micro Denier Polyester $=0.342$}

The aboveTable.5.4 shows the thickness of the fabric and the number of samples. Likewise readings were obtained from five different area of the sample in the same fabric and the average value gives the thickness of the fleece fabric.

\subsection{Thermal Conductivity:}

Table 3.5 Thermal conductivity testing

\begin{tabular}{|l|l|l|l|l|l|}
\hline $\begin{array}{l}\text { Sample } \\
\text { name }\end{array}$ & $\begin{array}{l}\text { Mean } \\
\text { Temp } \\
\text { (Deg } \\
\text { C) }\end{array}$ & $\begin{array}{l}\text { Delta } \\
\text { Temp } \\
\text { (Deg } \\
\text { C) }\end{array}$ & $\begin{array}{l}\text { Thermal } \\
\text { conductivity } \\
\text { W/m-k }\end{array}$ & $\begin{array}{l}\text { Thermal } \\
\text { resistance } \\
\text { M2 *k/w }\end{array}$ & $\begin{array}{l}\text { Temperature } \\
\text { gradient } \\
\text { OK/m }\end{array}$ \\
\hline Kapok & 0 & 10.08 & 0.115707 & 0.691542 & 125.96 \\
\hline $\begin{array}{l}\text { Kapok } \\
\text { with } \\
\text { LM }\end{array}$ & 0 & 10.01 & 0.033069 & 0.599670 & 504.83 \\
\hline
\end{tabular}

\section{Calculation}

\subsubsection{Thermal insulation of Kapok:}

Thermal conductivity of kapok $=0.115707$

Thickness $=10 \mathrm{~mm}$

Thermal Insulation $=$ thickness in $(\mathrm{m}) /$ thermal conductivity

$$
\begin{aligned}
& =0.001 / 0.115707 \\
& =0.0086 \mathrm{w} / \mathrm{mk}
\end{aligned}
$$

3.3.2 Thermal insulation of kapok with low melt polyester:

Thermal conductivity of kapok $=0.033069$

Thickness $=10 \mathrm{~mm}$

Thermal Insulation $=$ thickness in $(\mathrm{m}) /$ thermal conductivity

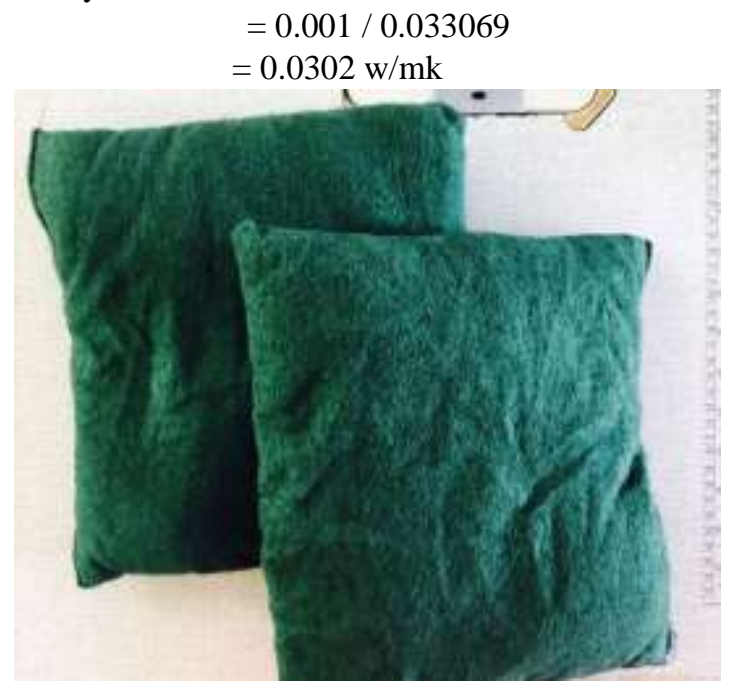

Thermal Conductivity Test Sample 


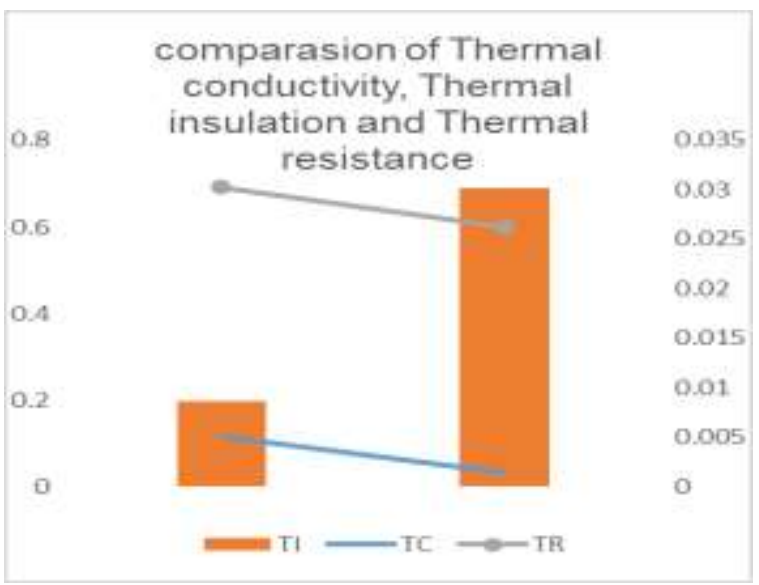

Fig.3.1 thermal property

From the Fig.3.1 shows that the thermal conductivity, thermal insulation, and thermal resistance of kapok and its blend. It showed the $100 \%$ kapok filling has higher thermal conductivity, Due to higher thermal resistance of kapok. Where the kapok with low melt polyester showed lesser thermal conductivity due to the lower thermal resistance of kapok and its blends

\subsection{Air Permiability:}

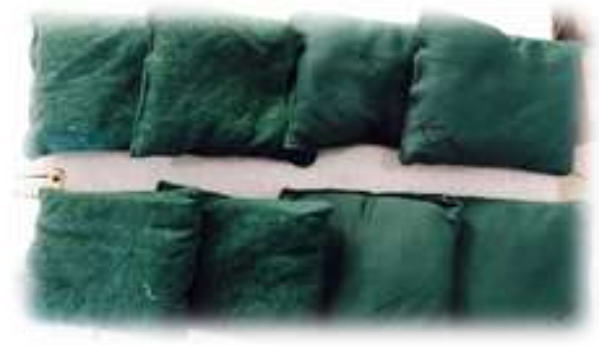

Air Permiability Test Sample

\begin{tabular}{|l|l|}
\hline Sample & $\begin{array}{l}\text { Air permeability } \\
(\mathrm{cm} 3 / \mathrm{cm} 2 / \mathrm{sec})\end{array}$ \\
\hline \multirow{4}{*}{$\begin{array}{l}\text { Sample } \\
\text { KAPOK }\end{array}$} & 4.48 \\
\cline { 2 - 3 } & 4.54 \\
\cline { 2 - 2 } & 3.79 \\
\cline { 2 - 2 } & 5.34 \\
\cline { 2 - 2 } Average & 4.56 \\
\hline C.V & 4.54 \\
\hline
\end{tabular}

Table 3.6 (a) air permeability sample-1

Table 3.6 (b) air permeability sample-2

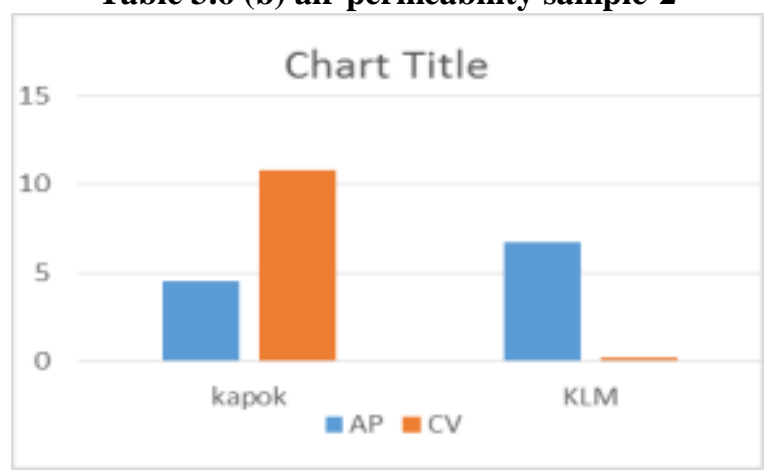

Fig.3.2 Air permeability
The Fig 3.2 shows the air permeability of kapok and its blends. Where the kapok blend with low melt polyester has high air permeability than the $100 \%$ kapok because of the structural property of kapok and low melt polyester.

\subsection{Water Vapour Permeability:}

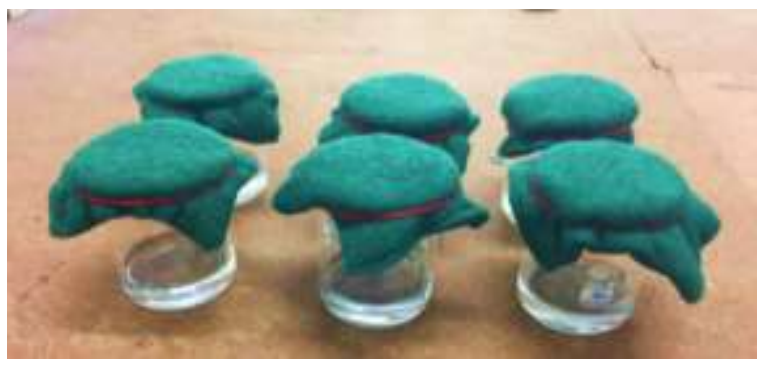

Water vapour permeability

\begin{tabular}{|l|l|}
\hline Sample & $\begin{array}{l}\text { Air permeability } \\
(\mathrm{cm} 3 / \mathrm{cm} 2 / \mathrm{sec})\end{array}$ \\
\hline \multirow{4}{*}{$\begin{array}{l}\text { Sample } \\
\text { KLM }\end{array}$} & 6.19 \\
\cline { 2 - 2 } & 7.22 \\
\cline { 2 - 2 } & 5.76 \\
\cline { 2 - 2 } Average & 9.29 \\
\cline { 2 - 2 } & 5.22 \\
\hline C.V & 6.74 \\
\hline
\end{tabular}

Test sample

\begin{tabular}{|l|l|l|l|l|l|}
\hline $\begin{array}{l}\text { SERIA } \\
\text { L NO. }\end{array}$ & $\begin{array}{l}\text { SAMPLE } \\
\text { S }\end{array}$ & $\begin{array}{l}\text { INITIA } \\
\text { L } \\
\text { VALU } \\
\text { E }\end{array}$ & $\begin{array}{l}\text { FINAL } \\
\text { VALU } \\
\text { E }\end{array}$ & $\begin{array}{l}\text { WEIGH } \\
\text { T LOSS }\end{array}$ & $\begin{array}{l}\text { WV } \\
\text { P }\end{array}$ \\
\hline 1 & Sample-1 & 75.42 & 74.06 & 1.36 & 1.37 \\
\hline 2 & Sample-2 & 74.33 & 72.94 & 1.39 & 1.40 \\
\hline 3 & Sample-3 & 74.51 & 73 & 1.51 & 1.52 \\
\hline 4 & Sample-4 & 75.62 & 73.2 & 1.42 & 1.43 \\
\hline 5 & Sample-5 & 76.73 & 75.24 & 1.49 & 1.44 \\
\hline 6 & Sample-6 & 79.19 & 77.83 & 1.36 & 1.37 \\
\hline
\end{tabular}

Table 3.7 water vapor permeability of kapok and its blends

In Table 3.7. water permeability test both fleece and micro denier polyester has not shown any significant changes because of its structural characteristics.

\subsection{Wicking:}

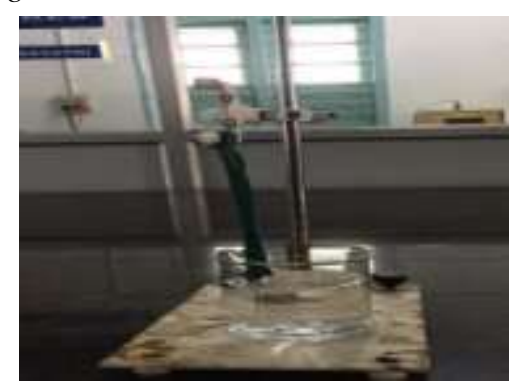

Published By: 

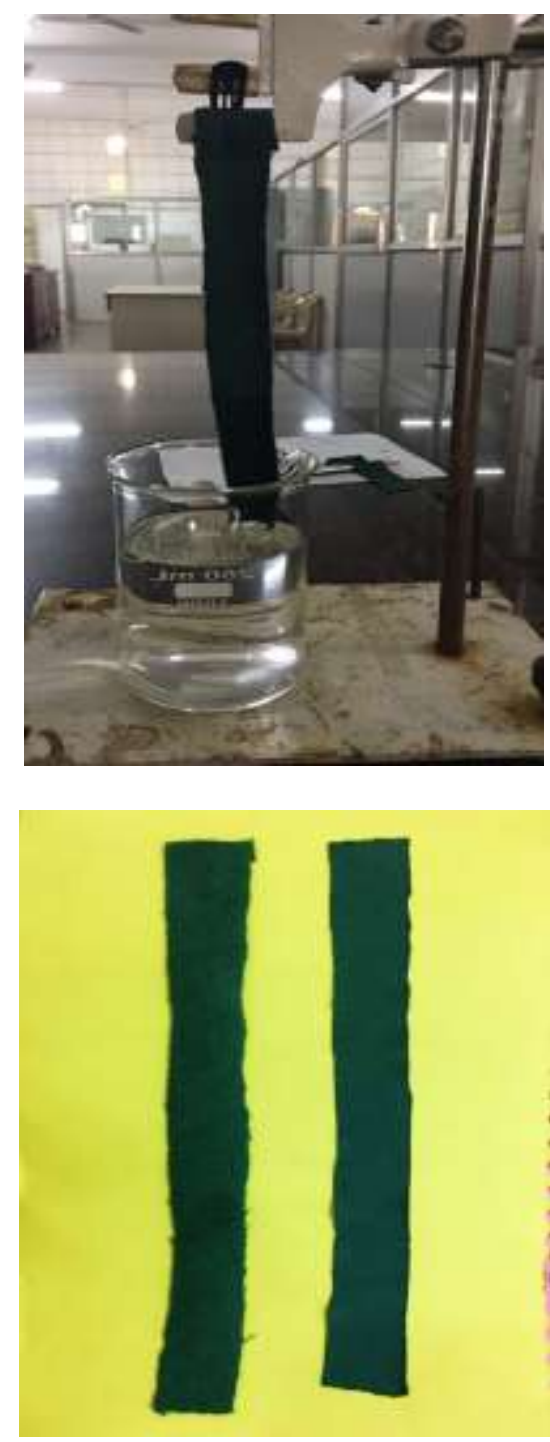

Wicking Test Sample

Table 3.8 Wicking of Fleece and Micro Denier Polyester

\begin{tabular}{|c|c|c|c|c|c|c|c|c|c|c|}
\hline $\begin{array}{l}\mathrm{Z} \\
\mathrm{S}\end{array}$ & \multicolumn{2}{|c|}{$\begin{array}{c}\text { Particular } \\
\text { s }\end{array}$} & \multicolumn{2}{|c|}{ Initial weight } & \multicolumn{2}{|c|}{ Final weight } & \multicolumn{2}{|c|}{$\begin{array}{l}\text { Heights In } \\
\text { CM }\end{array}$} & \multicolumn{2}{|c|}{ Time in sec } \\
\hline & $\begin{array}{l}\text { Fl } \\
\text { ee } \\
\text { ce }\end{array}$ & $\begin{array}{l}\mathrm{M} \\
\mathrm{DP}\end{array}$ & $\begin{array}{c}\text { Flee } \\
\text { ce }\end{array}$ & $\begin{array}{c}\text { MD } \\
P\end{array}$ & $\begin{array}{c}\text { Flee } \\
\text { ce }\end{array}$ & $\begin{array}{c}\mathrm{MD} \\
\mathrm{P}\end{array}$ & $\begin{array}{c}\text { Flee } \\
\text { ce }\end{array}$ & $\begin{array}{c}\mathrm{M} \\
\mathrm{DP}\end{array}$ & $\begin{array}{c}\text { Fleec } \\
\mathrm{e}\end{array}$ & $\begin{array}{c}\mathrm{MD} \\
\mathrm{P}\end{array}$ \\
\hline 1 & $\begin{array}{c}\mathrm{A} \\
1\end{array}$ & A3 & 1.27 & 0.93 & 2.83 & 1.91 & $.5-1$ & $0-1$ & 0.52 & $26 \mathrm{~s}$ \\
\hline 2 & $\begin{array}{l}\mathrm{A} \\
2\end{array}$ & A8 & 1.27 & 0.93 & 2.83 & 1.91 & $1-2$ & $1-2$ & 3.43 & $53 \mathrm{~s}$ \\
\hline 3 & $\begin{array}{l}\mathrm{A} \\
4\end{array}$ & A9 & 1.27 & 0.93 & 2.83 & 1.91 & $2-3$ & $2-3$ & 6.44 & 1.38 \\
\hline 4 & $\begin{array}{l}\mathrm{A} \\
5\end{array}$ & $\begin{array}{c}\text { A1 } \\
0\end{array}$ & 1.27 & 0.93 & 2.83 & 1.91 & $3-4$ & $3-4$ & 10.28 & 2.40 \\
\hline 5 & $\begin{array}{l}\mathrm{A} \\
6\end{array}$ & $\begin{array}{c}\mathrm{A} 1 \\
1\end{array}$ & 1.27 & 0.93 & 2.83 & 1.91 & $4-5$ & $4-5$ & 15.42 & 3.48 \\
\hline 6 & $\begin{array}{l}\mathrm{A} \\
7\end{array}$ & $\begin{array}{c}\text { A1 } \\
2\end{array}$ & 1.27 & 0.93 & 2.83 & 1.91 & $5-6$ & $5-6$ & 21.17 & 5.58 \\
\hline
\end{tabular}

The above Fig.3.3 represents the wick ability comparison of fleece fabric and micro denier polyester fabric where Fleece Fabric results in higher wick ability than Micro denier polyester due to less observance and keeps dry at all time.

\section{CONCLUSION}

In this project the development of multi-layer clothing using natural fiber based thermal insulation filling like kapok and kapok with low melt polyester were used. The fabric used for base layer and outer layer were Micro denier polyester and fleece, for the development of multi-layer extreme cold weather clothing. From the developed multilayer extreme cold weather clothing thermal conductivity, water vapor permeability, air permeability and wicking were analyzed, to optimize the thermal insulating layer that is suitable for multilayer cold weather clothing. The test results were analyzed and concluded as follows:

o $100 \%$ kapok has higher thermal conductivity than kapok with blends. Due to its natural thermal conductivity property

- In water permeability test both fleece and micro denier polyester has not shown any significant changes because of its structural characteristics.

○ In Air permeability test kapok with its blend has higher permeability when comparing to $100 \%$ kapok due to high resilient property of low melt polyester.

○ In wicking the Fleece fabric has higher wickability than micro denier polyester fabric due to its soft nature good moisture and wicking ability.

\section{REFERENCES}

1. Jing Gae,Wridong $\mathrm{Yu}$ and Ning Pan.Steructure and Properties of of Goosedown as a Material for Thermal insulation,Textile Research Journel,2007;77;617.

2. Lucas.A.M and Stettenheim.Structure of Feathers,Avain Anat Integument, 1972.

3. 3. Comis,D.Chicken Feathers;Eco Friendly Plastics of 21 st century, 1998.

4. Tatjana Rijiavec.Kapok in Technical Textiles,Kapok V Technicnich Tekstilijah,2008. 
5. Gammons.F.S.Cleaning and Seperating of Kapok Fiber from its Seeds and impurities,US Patent,1908.

6. Fengel.D.Studies on Kapok,Holzforschung,2000.voilume 54.

7. Wang.F.Comparissions of Thermal and Evoparative Resistances of Kapok Coats and Traditional down coats,Fibers and Textiles Journals,2010.volume 18.

8. Malgorzata Matusiak.Thermal Insulation Properties of Multilayer Textile Packages,Autex Jesearch Journrnal,2014.volume 14

9. Hes.L.Araujo,M.Thermal insulation and Thermal Contuctive Properties, Textile Research Journal,1996.

10. Vignesh Dhanabaln and Laga.S.K.Kapok a Perspective Fibre,Technical Textiles Journal.

11. Wishingeon.Absorbency of Micro Denier Textiles,Textiles for Emergency Savage,2000.

12. Marietta Georgia.Cold Weather Clothing,http://www.bsa 204.com,2004.

13. Raneush Babbu.V.Fabric Structure of Wicking,Journal of Engineered Fibers and Fabrics,2012.

14. Phillip Wayne Gibson.Air Permeability of Textile Material,Textile Research Journal,1999.

15. Ansell.N.Moisture of Wicking Fabric Specification,Hydra Tex.2004.

16. . Koger Brown.Polymer Testing,Elsevier Journal,2007.

17. Dusan Popovic.Thermal Properties of Textile Fabric Made of Natural Fibers,Elsevier Journal,2007.

18. Jakub Wiener.Wicking and Wetting in Textiles,Autex Research Journal,2003,volume3.

19. Nillison.T.MicrostructureofKapok,Holzforschung,2000,v olume 54.

20. Matusiak. M.Thermal Insulation Properties of Single and Multilayer Textiles,Fibers and Textile Research Journals,2006.

21. www.researchgate.com

22. www.onlineclothingstudy.com 